\title{
ChemComm
}

\section{Microwave-assisted solvothermal synthesis of zirconium oxide based metal-organic frameworks $\dagger$}

Cite this: Chem. Commun., 2013, 49, 3706

Received 16th January 2013,

Accepted 14th March 2013

DOI: $10.1039 /$ c3cc40368h

\author{
Weibin Liang and Deanna M. D’Alessandro*
}

www.rsc.org/chemcomm

Zirconium oxide based Metal-Organic Frameworks were synthesised using a rapid and efficient microwave-assisted solvothermal method that produced purer phases and higher quality crystalline products in significantly $(>95 \%)$ less time than the conventional heating method. A new amino-functionalised analogue has been synthesised exclusively using this microwaveassisted methodology.

Metal-Organic Frameworks (MOFs) are a rapidly expanding class of microporous materials which exhibit enormous structural and chemical diversity. ${ }^{1-3}$ By taking advantage of the vast array of inorganic and organic building blocks, a plethora of functional materials with promising applications have been obtained. ${ }^{2,4,5}$ One issue that has impeded the realworld application of many frameworks is their low stability, particularly under ambient conditions; ${ }^{6}$ for example, the archetypal framework $\left[\mathrm{Zn}_{4} \mathrm{O}(\mathrm{bdc})_{3}\right], \mathrm{MOF}-5$, where bdc = 1,4-benzenedicarboxylate, is prone to hydrolysis in air at ambient temperature. ${ }^{7-10}$

Recently, Serre and coworkers reported a series of porous zirconium MOFs with the general formula $\left[\mathrm{ZrO}\left(\mathrm{O}_{2} \mathrm{C}-\mathrm{X}-\mathrm{CO}_{2}\right)\right]$ ( $\mathrm{X}=\mathrm{C}_{6} \mathrm{H}_{4}, \mathrm{C}_{10} \mathrm{H}_{6}, \mathrm{C}_{12} \mathrm{H}_{8}$ and $\mathrm{C}_{12} \mathrm{~N}_{2} \mathrm{H}_{6} \mathrm{Cl}_{2}$ for MIL-140A, MIL140B, MIL-140C and MIL-140D, respectively), which comprise one-dimensional zirconium oxide chains connected by linear dicarboxylic acid ligands. ${ }^{11}$ This class of materials combines exceptional hydrophobicity with high chemical and mechanical stability which paves the way for their industrial application in areas such as catalysis, gas adsorption and gas separation processes.

Typically, MOFs are synthesised by mass diffusion, conventional electric heating (CE) and microwave heating (MW), ${ }^{12}$ while electrochemical, mechanochemical and sonochemical methods have been less commonly employed. ${ }^{12,13}$ Compared with

School of Chemistry, Building F1, University of Sydney, NSW, 2006, Australia. E-mail: deanna@chem.usyd.edu.au; Tel: +61 (2)93513777

† Electronic supplementary information (ESI) available: Experimental details, PXRD patterns, Le Bail refinements, TGA curves and sorption data. See DOI: $10.1039 / \mathrm{c} 3 \mathrm{cc} 40368 \mathrm{~h}$ other methods, the MW synthesis protocol offers distinct advantages in terms of the reduction in the synthesis time and the increase in energy efficiency that favours industrial production processes. ${ }^{14-19}$ The present work demonstrates the efficient synthesis of the isoreticular frameworks MIL-140A-MW and MIL-140B-MW using microwave irradiation, in addition to the synthesis of a new framework, MIL-140A- $\mathrm{NH}_{2}-\mathrm{MW}$ ([ZrO(abdc)], where abdc $=$ 2-amino-1,4-benzenedicarboxylate).

The reaction parameters employed for the MW synthesis of the MIL-140 frameworks were analogous to those reported previously in the literature for the CE heating method, ${ }^{11}$ with only the synthesis time being varied. The reaction medium consisting of $0.25 \mathrm{mmol} \mathrm{ZrCl}_{4}, 0.5 \mathrm{mmol}$ of a given ligand (1,4-benzenedicarboxylic acid $\left(\mathrm{H}_{2} \mathrm{bdc}\right)$, 2,6-naphthalenedicarboxylic acid $\left(\mathrm{H}_{2} \mathrm{ndc}\right)$ or 2-amino-1,4-benzenedicarboxylic acid $\left(\mathrm{H}_{2} \mathrm{abdc}\right)$ ) and $2.5 \mathrm{~mL}$ DMF was heated at a temperature of $220{ }^{\circ} \mathrm{C}$ to produce MIL-140A-CE and MIL-140B-CE after 16 and $6 \mathrm{~h}$, respectively, under CE heating, compared with MIL140A-MW and MIL-140B-MW produced after 15 minutes under MW heating (ramp time $=2 \mathrm{~min}$, hold time $=15 \mathrm{~min})(\mathrm{ESI} \dagger)$. Initial attempts to produce the amino-functionalised framework incorporating the abdc ligand under CE heating using the same conditions (temperature, concentration, stoichiometry) and only varying the acetic acid/ $\mathrm{ZrCl}_{4}$ ratio produced the UiO66- $\mathrm{NH}_{2}$ framework exclusively (ESI $\dagger$ ), ${ }^{20}$ rather than the desired MIL-140A- $\mathrm{NH}_{2}$ phase; the possibility of generating the latter phase using alternate conditions under CE heating cannot, however, be excluded.

Previous reports concerning the MW synthesis of MOFs have described order of magnitude increases in the reaction rates compared with CE heating, principally due to localised superheating resulting from (i) dipolar polarisation (the principal heat-generation pathway for the solvents which results in rapid molecular rotation induced by the oscillation of the electric field), (ii) enhanced refluxing within the sealed vessel, (iii) the presence of electrically conducting materials, and (iv) the generation of gas plasma from absorbed gases. ${ }^{15,21}$ In the present case, the superheating effect explains why it is possible to perform the MW synthesis using shorter reaction 


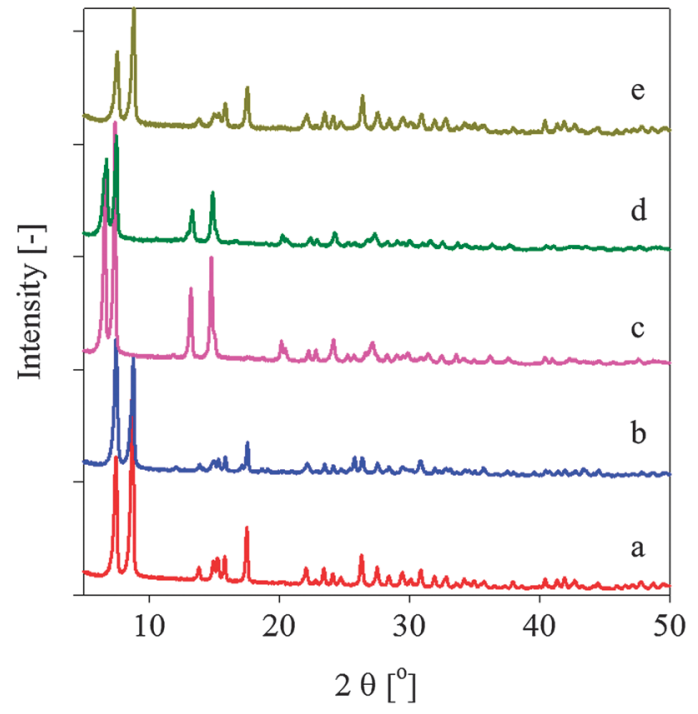

Fig. 1 PXRD patterns of (a) MIL-140A-MW, (b) MIL-140A-CE, (c) MIL-140B-MW, (d) MIL-140B-CE and (e) MIL-140A-NH - -MW

times compared with the conventional solvothermal synthesis method.

The crystallinity of the frameworks prepared using the two synthesis protocols was examined using powder X-ray diffraction (PXRD) analysis (Fig. 1). The frameworks synthesised via MW heating exhibited higher crystallinities than their counterparts obtained from CE heating, as evidenced by the reduced linewidths and more intense diffraction peaks in the former case. The positions and relative intensities of the peaks in the experimental PXRD patterns of MIL-140A-MW and MIL140B-MW along with the cell parameters calculated from Le Bail refinement were in very good agreement with those obtained for MIL-140A-CE and MIL-140B-CE, respectively (ESI + ). The PXRD patterns and cell parameters for the two frameworks synthesised by CE heating were also in good agreement with those reported in the literature, ${ }^{11}$ however, compared with the simulated pattern, the PXRD for MIL140A-CE exhibited a mixture of two phases: additional peaks at $2 \theta=12.1^{\circ}, 17.1^{\circ}$, and $25.9^{\circ}$ corresponded to the UiO-66 impurity (ESI $)^{22} .^{22}$

The rapid heating rate employed in the MW synthesis method $\left(25{ }^{\circ} \mathrm{C}\right.$ to $220{ }^{\circ} \mathrm{C}$ within $\left.2 \mathrm{~min}\right)$ was found to be critical to the improvement in the product purity compared with $\mathrm{CE}$ heating. Recently, Serre and coworkers hypothesised that the MIL-140 phase may be the recrystallisation product of the UiO phase ${ }^{11}$ While the latter is initially formed at low temperatures $\left(150{ }^{\circ} \mathrm{C}\right.$ for UiO-66), ${ }^{22}$ a further increase in the temperature leads to dissolution of this phase and recrystallisation of MIL-140 at $220{ }^{\circ} \mathrm{C}$. In the present case, even after $16 \mathrm{~h}$ under CE heating, the UiO-66 phase persisted in MIL-140A-CE, and a further increase in the reaction time to $18 \mathrm{~h}$ did not improve the phase purity of the product (ESI $\dagger$ ). Furthermore, under MW heating, an increase in the ramp time from 2 min to $1 \mathrm{~h}$ (target temperature: $220{ }^{\circ} \mathrm{C}$ ) led to the appearance of the UiO-66 phase impurity in the PXRD patterns of MIL-140A-MW (ESI + ). Thus, the use of a rapid ramp rate in the MW heating protocol is key

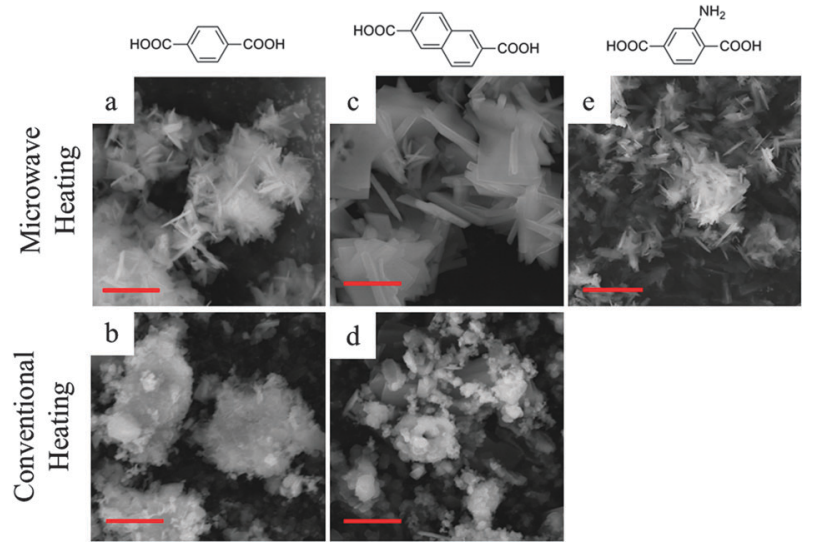

Fig. 2 SEM images of (a) MIL-140A-MW, (b) MIL-140A-CE, (c) MIL-140B-MW, (d) MIL-140B-CE and (e) MIL-140A-NH $-\mathrm{MW}$ (scale bar $=3 \mu \mathrm{m}$ ).

to the improved phase purity and crystallinity of the MIL-140 frameworks synthesised herein.

The importance of the microwave methodology was further demonstrated by the synthesis of a new isoreticular framework incorporating abdc, MIL-140A- $\mathrm{NH}_{2}-\mathrm{MW}$, which could not be attained in initial trials using the CE heating method (varying the acetic acid/ $/ \mathrm{ZrCl}_{4}$ ratio). Regardless of the reaction time (12 and $24 \mathrm{~h}$ ) and the concentration of the acetic acid modulator, only UiO-66- $\mathrm{NH}_{2}$ could be obtained using the $\mathrm{CE}$ heating method $(\mathrm{ESI}+)^{20}{ }^{20}$ The close similarity of the PXRD patterns of MIL-140A-MW and MIL-140A- $\mathrm{NH}_{2}-\mathrm{MW}$ confirmed the isostructural nature of the frameworks (Fig. 1a and e).

Fig. 2 shows the SEM images of the frameworks synthesised under MW irradiation at $220{ }^{\circ} \mathrm{C}$ for $15 \mathrm{~min}$ and using CE heating at $220{ }^{\circ} \mathrm{C}$ for more than $6 \mathrm{~h}(16 \mathrm{~h}$ for MIL-140A-CE and $6 \mathrm{~h}$ for MIL-140B-CE). The materials synthesised by MW heating appeared as plate-like crystallites (Fig. 2a, c and e), in comparison with the relatively more disordered nature of the materials obtained by CE heating (Fig. $2 \mathrm{~b}$ and d). In particular, the irregular clusters observed in the latter cases may be assigned to the UiO impurities which were detected in the PXRD patterns (ESI $\dagger$ ). A comparison of the SEM images shows that the materials synthesised under MW irradiation (Fig. 2a and c) exhibit a higher degree of crystallinity than those synthesised via the CE heating method (Fig. 1b and d).

All frameworks, including the newly synthesised MIL-140A$\mathrm{NH}_{2}-\mathrm{MW}$, exhibited pronounced thermal stabilities up to ca. $450{ }^{\circ} \mathrm{C}$. In general, thermogravimetric analysis (TGA) of the $\mathrm{CE}$ and MW synthesised samples revealed two distinct weight loss steps corresponding to the loss of methanol employed in the washing procedure, and to the decomposition of the organic linkers and the formation of zirconium oxide, respectively (ESI $\dagger)^{23,24}$ The theoretical and experimental weight loss profiles for MIL-140A-MW, MIL-140A-CE, MIL-140B-MW and MIL-140A- $\mathrm{NH}_{2}-\mathrm{MW}$ (calculated from their chemical formulae, ESI $\dagger$ ) were in good agreement; however, the experimentally determined weight loss for MIL-140B-CE (57.9\%) was less than the theoretical value (61.6\%).

The experimental and theoretical Brunauer-Emmett-Teller (BET) surface areas for all synthesised samples are summarised 
Table 1 Comparison of BET surface areas determined from $\mathrm{N}_{2}$ sorption isotherms at $77 \mathrm{~K}$ over the range $0-1$ bar for the frameworks

\begin{tabular}{|c|c|c|c|}
\hline Phase $^{a}$ & $\begin{array}{l}\text { Theoretical } \\
S_{\text {BET }}\left[\mathrm{m}^{2} \mathrm{~g}^{-1}\right]^{11}\end{array}$ & $\begin{array}{l}\text { Reported } \\
S_{\text {BET }}\left[\mathrm{m}^{2} \mathrm{~g}^{-1}\right]^{11}\end{array}$ & $\begin{array}{l}\text { Experimental } \\
S_{\text {BET }}\left[\mathrm{m}^{2} \mathrm{~g}^{-1}\right]\end{array}$ \\
\hline MIL-140A-MW & 360 & - & $337(8)$ \\
\hline MIL-140A-CE & 360 & $415(10)$ & $585(16)$ \\
\hline MIL-140B-MW & 429 & - & $438(8)$ \\
\hline MIL-140B-CE & 429 & $460(10)$ & $398(9)$ \\
\hline MIL-140A-NH - -MW & - & - & $234(6)$ \\
\hline
\end{tabular}

${ }^{a}$ MW: microwave heating, temperature ramp to $220{ }^{\circ} \mathrm{C}$ within $2 \mathrm{~min}$; CE: conventional electric heating; the reaction vessel was placed in a pre-heated oven at $220{ }^{\circ} \mathrm{C}$.

in Table 1 (the $\mathrm{N}_{2}$ sorption isotherms are shown in the ESI $\dagger$ ). The experimental BET surface areas were determined as 337(8) and $438(8) \mathrm{m}^{2} \mathrm{~g}^{-1}$, respectively, for MIL-140A-MW and MIL140B-MW, which were in good agreement with the theoretical values (360 and $429 \mathrm{~m}^{2} \mathrm{~g}^{-1}$ for MIL-140A and MIL-140B, respectively). ${ }^{11}$ For MIL-140A-CE and MIL-140B-CE synthesised by CE heating, the BET surface areas were calculated to be 585(16) and 398(9) $\mathrm{m}^{2} \mathrm{~g}^{-1}$, respectively. The discrepancy between the experimental and theoretical surface areas for MIL-140A-CE (62.5\% higher) is attributed to the presence of the relatively more porous UiO-66 impurity within the product (the BET surface area for UiO-66 was reported to be $969 \mathrm{~m}^{2} \mathrm{~g}^{-1}$ ). ${ }^{25}$ The surface area for MIL-140A-NH $\mathrm{N}_{2}-\mathrm{MW}$ was 234(6) $\mathrm{m}^{2} \mathrm{~g}^{-1}$, which was $30 \%$ lower than that for MIL-140A-MW, consistent with the reduced pore space and the increased overall weight of the functionalised framework which results from the introduction of the amino group.

In summary, the application of a microwave-assisted solvothermal method to frameworks in the MIL-140 series produces purer phases and higher quality crystalline products in significantly ( $>95 \%)$ less time than the conventional heating method. A new amino-functionalised analogue, which was unattainable using the CE heating method within the range of synthesis conditions explored in this work, was exclusively synthesised using this microwave-assisted methodology. The extension of the MW method to a wider range of MIL-140 analogues with other functional groups will pave the way towards new materials for gas separation and catalysis, amongst other applications. The development of rapid and efficient synthesis methods for MOFs which favour industrial production represents a critical aspect in their eventual deployment at the industrial scale.

\section{Notes and references}

1 M. O'Keeffe and O. M. Yaghi, Chem. Rev., 2012, 112, 675-702.

2 A. Bétard and R. A. Fischer, Chem. Rev., 2012, 112, 1055-1083.

3 F. A. Almeida Paz, J. Klinowski, S. M. F. Vilela, J. P. C. Tomé, J. A. S. Cavaleiro and J. Rocha, Chem. Soc. Rev., 2012, 41, 1088-1110.

4 A. Corma, H. García, F. X. Llabrés and I. Xamena, Chem. Rev., 2010, 110, 4606-4655.

5 K. K. Tanabe and S. M. Cohen, Chem. Soc. Rev., 2011, 40, 498-519.

6 D. M. D'Alessandro, B. Smit and J. R. Long, Angew. Chem., Int. Ed., 2010, 49, 6058-6082.

7 S. S. Kaye, A. Dailly, O. M. Yaghi and J. R. Long, J. Am. Chem. Soc., 2007, 129, 14176-14177.

8 S. J. Yang, J. Y. Choi, H. K. Chae, J. H. Cho, K. S. Nahm and C. R. Park, Chem. Mater., 2009, 21, 1893-1897.

9 M. Sabo, A. Henschel, H. Frode, E. Klemm and S. Kaskel, J. Mater. Chem., 2007, 17, 3827-3832.

10 J. A. Greathouse and M. D. Allendorf, J. Am. Chem. Soc., 2006, 128, 10678-10679.

11 V. Guillerm, F. Ragon, M. Dan-Hardi, T. Devic, M. Vishnuvarthan, B. Campo, A. Vimont, G. Clet, Q. Yang, G. Maurin, G. Ferey, A. Vittadini, S. Gross and C. Serre, Angew. Chem., Int. Ed., 2012, 51, 9188.

12 N. Stock and S. Biswas, Chem. Rev., 2011, 112, 933-969.

13 T. R. Cook, Y.-R. Zheng and P. J. Stang, Chem. Rev., 2012, 113, 734-777.

14 E. Haque, N. A. Khan, C. M. Kim and S. H. Jhung, Cryst. Growth Des., 2011, 11, 4413-4421.

15 J. Klinowski, F. A. Almeida Paz, P. Silva and J. Rocha, Dalton Trans., 2011, 40, 321-330.

16 M. Kim, S. J. Garibay and S. M. Cohen, Inorg. Chem., 2011, 50, 729-731.

17 Z. Xiang, D. Cao, X. Shao, W. Wang, J. Zhang and W. Wu, Chem. Eng. Sci., 2010, 65, 3140-3146.

18 X.-F. Wang, Y.-B. Zhang, H. Huang, J.-P. Zhang and X.-M. Chen, Cryst. Growth Des., 2008, 8, 4559-4563.

19 O. Karagiaridi, M. B. Lalonde, W. Bury, A. A. Sarjeant, O. K. Farha and J. T. Hupp, J. Am. Chem. Soc., 2012, 134, 18790-18796.

20 M. Kandiah, M. H. Nilsen, S. Usseglio, S. Jakobsen, U. Olsbye, M. Tilset, C. Larabi, E. A. Quadrelli, F. Bonino and K. P. Lillerud, Chem. Mater., 2010, 22, 6632-6640.

21 Y. Yoo and H. K. Jeong, Chem. Commun., 2008, 2441-2443.

22 J. H. Cavka, S. Jakobsen, U. Olsbye, N. Guillou, C. Lamberti, S. Bordiga and K. P. Lillerud, J. Am. Chem. Soc., 2008, 130, 13850-13851.

23 A. Schaate, P. Roy, A. Godt, J. Lippke, F. Waltz, M. Wiebcke and P. Behrens, Chem.-Eur. J., 2011, 17, 6643-6651.

24 A. Schaate, S. Dühnen, G. Platz, S. Lilienthal, A. M. Schneider and P. Behrens, Eur. J. Inorg. Chem., 2012, 790-796.

25 S. Chavan, J. G. Vitillo, D. Gianolio, O. Zavorotynska, B. Civalleri, S. Jakobsen, M. H. Nilsen, L. Valenzano, C. Lamberti, K. P. Lillerud and S. Bordiga, Phys. Chem. Chem. Phys., 2012, 14, 1614-1626. 